\title{
Considerações sobre reimplantes dentários: condutas clínicas e ortodônticas frente a estas situações.
} Considerations about teeth replants: clinic and orthodontic procedures in these situations.

Daniela Soeiro de Souza Rezende* Márcia Delgado de Ávila* Eduardo Silveira Ferreira**

\section{Resumo}

O objetivo deste trabalho é, usando uma revisão de literatura, estabelecer que grau de anquilose dentária ou reabsorção radicular permite que dentes reimplantados sejam movimentados com a utilização de aparelhos ortodônticos.

São abordados aspectos referentes a avulsão e ao reimplante dental, tais como etiologia, condutas clínicas e prognóstico. Uma revisão de literatura sobre movimento dentário ortodôntico também é apresentada. De acordo com a maioria dos autores, a anquilose, sequiela frequiente após reimplante, inviabiliza o movimento ortodôntico. Entretanto, a ausência de sinais de reabsorção em um período mínimo de um ano, viabiliza o tratamento ortodôntico quando necessário.

\section{Unitermos \\ Anquilose, movimento ortodôntico, reimplante dentário.}

\section{INTRODUCẼOO}

A cavidade bucal é uma região, pela sua posição, passível de sofrer traumatismos. As injúrias na dentição e nos tecidos moles são comuns, e seus efeitos na função e na estética facial merecem atenção do cirurgião-dentista.

A Ortodontia pode e deve ter um papel importante na reabilitação dos pacientes que sofreram algum tipo de traumatismo, já que a oclusão reabilitada oportuniza a base para que as outras estruturas faciais sejam reconstruídas.

Entre os diversos tipos de traumatismos que podem ocorrer, a avulsão é o que requer maior atenção, porque além de implicações estéticofuncionais, também provoca alterações de aspecto psicológico decorrentes da perda dental imediata.

Quando indicado, o reimplante é uma alternativa de tratamento conservador que visa o restabelecimento da estética e função, mesmo que temporariamente, pois protela a necessidade protética no caso de insucesso.

0 sucesso do reimplante depende quase que exclusivamente do período do dente fora do alvéolo e do meio de conservação do mesmo. Os danos ocorridos ao ligamento periodontal durante este intervalo de tempo estão relacionados a um possível desenvolvimento de anquilose (reabsorção por substituição). A intensidade e o tipo de injúria irão determinar o grau de lesão na polpa e no periodonto.
De acordo com a literatura, dentes anquilosados não são passíveis de movimentação ortodôntica visto que este se realiza às custas do remodelamento ósseo pelo processo de pressão/tensão do ligamento periodontal.

A proposição deste estudo é, através de uma revisão de literatura, estabelecer que grau de anquilose dentária ou de reabsorção radicular permite que o dente seja movimentado com a utilização de aparelhos ortodônticos.

\section{ETIOLOGIA DOS \\ TRAUMATISMOS DENTÁRIOS}

Os fatores etiológicos dos traumatismos são principalmente prática de esportes, brigas e em baixa prevalência, a falta de coordenação motora e acidentes automobilísticos ${ }^{10}$.

Há uma relação significativa entre a protrusão dental e a incidência de lesões em dentes anteriores, principalmente em meninos com idade entre 8 e 12 anos. 0 tratamento ortodôntico da maloclusão de Classe II de Angle severa é proposto como um meio efetivo de prevenir injúrias dentárias ${ }^{16}$.

Segundo estudo realizado por Hunter em 1990, outros fatores também predispõem ou favorecem a ocorrência de traumatismos. São eles ${ }^{9}$ :

- Maloclusão de Classe II com acentuado trespasse horizontal

- Mordida profunda ( sobremordida exagerada )

- Mordida cruzada uni ou bilateral

- Prognatismo mandibular

Espaçamento dentário generaliza- do na região anterior

- Diastema entre os incisivos centrais

- Agenesia de incisivos laterais

- Baixa inserção gengival

- Severo apinhamento anterior

A avulsão dos dentes permanentes é mais comum na dentição jovem, onde o desenvolvimento radicular ainda está incompleto e o periodonto é bastante resiliente. Porém, a completa saída do dente do seu alvéolo não é um acontecimento muito frequiente, ocorrendo entre 1 a $16 \%$ nos casos relatados na literatura ${ }^{9}$.

\section{MOVIMENTO DENTÁRIO ORTODÔNTICO}

A integridade do periodonto, em sua totalidade é um pré-requisito no movimento dentário ortodôntico ${ }^{17}$. Como oposição ao acontecimento traumático, a movimentação ortodôntica do dente é usualmente uma resposta vagarosa para uma força leve. No entanto, o processo é considerado por alguns como sendo um trauma controlado das estruturas de suporte do dente. Isso porque mudanças similares àquelas relatadas após uma injúria traumática podem ser comuns ${ }^{13}$.

O ligamento periodontal ocupa cerca de $0,5 \mathrm{~mm}$ entre a parede do alvéolo e o cemento, sendo responsável pela articulação dental. É constituído principalmente por fibras colágenas, que são entremeadas por vasos sangüíneos, elementos celulares, terminações nervosas e fluido intersticial ${ }^{3}$.

* Cirurgiã-Dentista graduada pela FO-UFRGS.

** Professor Assistente da Disciplina de Ortodontia da UFRGS.

Mestre em Ortodontia pela UFRJ. 
Os vasos sangüíneos são responsáveis pela nutrição do ligamento periodontal, assim como servirão de via de acesso para as células responsáveis pela remodelação do osso cortical e ligamentos ${ }^{3}$.

O osso é o tecido mais plástico do organismo, adaptando-se às forças funcionais que sobre ele se manifestam. Sua reação é no sentido de depositar tecido ósseo nas áreas submetidas às forças de tração, e reabsorver nas áreas onde há pressão ${ }^{3}$.

A movimentação ortodôntica somente é possível graças a esta propriedade plástica do osso alveolar sendo porém muito mais complexa que uma simples remodelação, pela presença de ligamento periodontal ${ }^{3}$.

As reações locais do tecido são influenciadas pelas características anatômicas do osso de suporte dentro do qual o dente deve ser movimentado, pela atividade fisiológica dos tecidos que circundam o dente e pela aplicação de força ${ }^{11}$.

A força ótima é definida como a força ideal capaz de produzir movimento ortodôntico. Burstone define como aquela que proporciona movimentação rápida, sem desconforto para o paciente e sem dano tissular. Assim, quando aplica-se uma força ótima, a pressão sobre o ligamento periodontal preservará sua vitalidade em toda sua extensão e iniciará uma resposta celular de aposição e reabsorção de máxima intensidade ${ }^{3}$.

\section{REABSORCÕES}

As exigências básicas para uma ótima cicatrização de um dente avulsionado é que esse fique fora do seu alvéolo o menor período de tempo possível, e que a conservação fora do alvéolo seja feita em um meio fisiológico de modo que a contaminação do dente seja eliminada ou reduzida. Se essas condições forem atendidas, podem ser esperados os seguintes evientos de cicatrização ${ }^{2}$ :

Revascularização do ligamento periodontal rompido rompidas

União das fibras de Sharpey

Formação de uma nova adesão gengival

Revascularização e reinervação da polpa.

Frente a um dano físico ou contaminação bacteriana da polpa ou do ligamento periodontal, ocorrem aberrações na cicatrização. Assim, se houver um dano menor da camada mais interna do ligamento, o local será reabsorvido por macrófagos e osteoclastos, resultando na escavação da superfície da raiz. Após algumas semanas, esta cavidade de reabsorção será reparada por um novo cemento e pelas fibras de Sharpey ${ }^{2}$.

$\mathrm{Na}$ formação inicial da cavidade, se toxinas de uma eventual infecção no canal ou nos túbulos dentinários atravessarem a extensão do cemento, poderão atingir até a superfície radicular externa. O resultado deste evento é a continuação do processo osteoclástico e a progressiva reabsorção da superfície radicular, que por fim, perfura o canal. Por outro lado, se a infecção no canal e nos túbulos for eliminada por uma terapia endodôntica, a atividade osteoclástica cessa e a cicatrização com novo cemento e fibras de Sharpey é completada ${ }^{2}$.

Quando ocorre um dano de moderado a extenso na camada mais interna do ligamento periodontal, ocorrerá um processo de cicatrização competitiva, pois as células do ligamento intacto adjacente tentarão invadir e reparar o local da lesão, exatamente como as células do osso alveolar oposto, que tentarão preencher a região traumatizada com novo osso. Após aproximadamente duas semanas, a invasão pode criar uma anquilose, cujo o destino dependerá da extensão do dano do ligamento periodontal e da existência de algum movimento funcional do dente lesado durante o período de cicatrização. Se a lesão do ligamento for somente mínima e o dente ainda não tiver sido imobilizado, a função irá estimular a remoção osteoclástica da ponte óssea (isto é, anquilose transitória) ${ }^{2}$.

Se durante a revascularização pulpar, as bactérias alcançarem o tecido pulpar isquêmico, seja através de uma lacuna no ligamento, seja pela corrente sangüínea (anacorese) ou ainda pelos túbulos dentinários, como ocorre após uma fratura coronária, o processo de revascularização cessará e uma área de inflamação demarcada por leucócitos se estabelecerá. Essa área de leucócitos irá separar a polpa isquêmica da área infectada do tecido cicatrizante e invasor. Caso aconteça uma lesão concomitante do ligamento, ocorrerá uma reabsorção radicular inflamatória externa e progressiva ${ }^{2}$.

\section{REABSORÇÃO DE SUPERFÍCIE}

É a resposta a uma lesão limitada ao ligamento periodontal ou à superfície radicular que, subseqüentemente, recupera-se através do ligamento periodontal intacto adjacente. Essas ca- vidades de reabsorção estão sempre presentes na superfície radicular após o reimplante, mas normalmente não podem ser demonstradas através de radiografia devido às suas dimensões pequenas ${ }^{1}$.

Outro aspecto que a distingue é a natureza autolimitante do processo de reabsorção. É importante lembrar que esse processo não requer tratamento

\section{REABSORÇ̃̃O INFLAMATÓRIA}

É sabido que a reabsorção inflamatória progressiva é relacionada a dentes com traumatismo severo ${ }^{1}$.

Esta pode ser definida como a resposta a uma lesão combinada ao ligamento periodontal e à polpa. Quando uma cavidade de reabsorção na superfície radicular expõe os túbulos dentinários e esses túbulos comunicamse com o tecido pulpar necrótico infectado, pode ocorrer inflamação no ligamento periodontal e estímulo da atividade de reabsorção ${ }^{1}$.

Tão logo for diagnosticada a reabsorção inflamatória, o tratamento endodôntico deve ser iniciado, uma vez que o processo de reabsorção prossegue em velocidade de até $0,1 \mathrm{~mm}$ por dia. Caso o tratamento não seja iniciado imediatamente, essa velocidade resultará em rápida perfuração do canal radicular ${ }^{1}$

Em casos nos quais grandes áreas da raiz foram reabsorvidas, a cicatrização pode ser em forma de anquilose. Isso poderia ser explicado pelo fator tamanho. Há evidência experimental para sugerir que a extensão da lesão à superfície radicular é decisiva para o desenvolvimento da anquilose ${ }^{1}$.

\section{REABSORCẼO POR \\ SUBSTITUICGÃO (ANQUILOSE)}

É conceituada como o processo mais severo de reabsorção, sendo um problema clínico que inviabiliza o movimento dentário ortodôntico. A anquilose acontece tanto na dentição decídua como na permanente de uma criança em crescimento, podendo induzir uma relação oclusal defeituosa. 0 s fatores etiológicos da anquilose vão desde o trauma até problemas metabólicos como endodônticos ou genéticos

A anquilose é uma complicação comum de traumatismos mecânicos, principalmente em dentes reimplantados. A anquilose se origina quando o esmalte, a dentina ou o cemento começam a ser substituídos por tecido ósseo como uma direta extensão do processo alveolar ${ }^{12}$.

A percussão de um dente 
anquilosado emite um som metálico em contraste com o som abafado do dente normal. Radiograficamente a anquilose pode ser diagnosticada como uma mancha no ligamento periodontal ${ }^{12}$.

O desenvolvimento de anquilose está fortemente relacionado à extensão do dano ao ligamento periodontal na superfície radicular do dente avulsionado durante o período extra-alveolar. Após cinco minutos de armazenamento a seco, os primeiros sinais de anquilose já se manifestam, e, após vinte minutos no mesmo meio, a anquilose afetará os dentes reimplantados com formação radicular completa. Em dentes com ápices abertos, o período crítico de armazenamento a seco parece ser de quarenta minutos. Se os dentes são armazenados em meios úmidos (saliva ou solução salina), a armazenagem extensa tem apenas um efeito moderado sobre a cicatrização do ligamento periodontal. A armazenagem longa em meios não-físiológicos, por exemplo, água de torneira, levará a extensa anquilose ${ }^{1}$.

Deve-se considerar que a anquilose pode ocorrer mesmo com a sobrevida da polpa, uma vez que a polpa é menos sensível ao dano externo ${ }^{1}$.

Se o local de anquilose inicial é limitado, o processo anquilótico pode ser temporário, sendo eliminado pelo processo de reparo do ligamento periodontal durante o primeiro ano após a lesão. Esse processo depende aparentemente da função normal do dente (isto é, ausência de esplintagem rígida). Durante a função normal no período de cicatrização ou reparo, as forças são transmitidas ao ligamento periodontal, as tensões criadas nos locais de anquilose aparentemente favorecem sua reabsorção. Assim, o primeiro princípio de tratamento para prevenção da anquilose permanente parece ser a omissão de fixação rígida após o reimplante ${ }^{1}$.

A técnica de Biederman foi descrita para luxação e liberação de um dente anquilosado após intrusão que é quase idêntica aos primeiros movimentos da extração dentária, segurando firmemente com o fórceps e movimentando no sentido vestíbulo-lingual ou mesio-distal. 0 objetivo é romper a ponte óssea da anquilose sem injuriar os vasos do ápice. Um aspecto importante da técnica é a imediata aplicação de força ortodôntica. 0 autor recomenda a observação do dente após a luxação, e se nenhuma mudança ocorrer em seis meses, deve-se repetir o procedimento. A experiência do autor mostra que se não for aplicada força ortodôntica o dente voltará a anquilosar e, em muitos casos, a anquilose pode ocorrer mesmo com a força ${ }^{15}$.

O tratamento endodôntico não tem efeito sobre a reabsorção por substituição, e o resultado final é a perda do dente (Figuras 3 e 4). A progressão do processo pode ser lenta. Um dente anquilosado pode ser mantido em boca por anos ${ }^{5}$. A anquilose impedirá o crescimento daquela porção do processo alveolar que contém o dente reimplantado, que no final resultará em infra-oclusão, existem dois tratamentos alternativos: Extração ou luxação e extrusão ortodônticas ${ }^{1}$.

\section{CONDUTAS CLÍNICAS}

O reimplante é indicado para pacientes jovens, onde uma prótese fixa é prematura. É possivel que um dente reimplantado fique permanentemente e com sucesso em boca ${ }^{14}$.

A informação mais efetiva é que dentes avulsionados podem ser salvos e que um passo inicial necessário em relação ao tratamento bem-sucedido é o imediato reimplante pelo paciente, pais ou parentes. Isso melhorará significativamente a cicatrização. As exigências básicas para uma ótima cicatrização é que o dente fique fora do seu alvéolo pelo menor tempo possível, que a conservação fora do alvéolo seja feita em um meio fisiológico de modo que a contaminação do dente seja eliminada, reduzida ou controlada por antibióticos. Colocando-se o dente em saliva, o ligamento periodontal é imediatamente protegido do efeito danoso da secagem. O dente pode ser mantido nesse local por várias horas antes que possa ser observado um efeito visível na cicatrização periodontal e pulpar. Entretanto, se uma solução salina fisiológica estiver imediatamente disponível, a armazenagem neste meio será preferida, uma vez que tem sido demonstrado resultar em cicatrização periodontal ligeiramente melhor ${ }^{1}$.

O reimplante por si só, é um procedimento relativamente simples. Contudo, certos procedimentos são essenciais para minimizar o dano ao ligamento periodontal e à polpa. Esses procedimentos incluem a limpeza adequada do dente e do alvéolo e o reimplante atraumático. Na maioria dos casos, isso implica em reimplante por dentista experiente mesmo à custa de um período extra-oral mais longo na condição de que o dente avulsionado seja mantido num meio de armazenagem adequada até o reimplante ${ }^{1}$.
A contenção representa um fator controvertido, quer em relação ao tipo, quer em relação ao tempo de permanência. $O$ dispositivo ideal deve ser passivo e atraumático, flexível, permitir testes de vitalidade e acesso endodôntico, ser de fácil aplicação e remoção. A imobilização não rígida permite um arranjo funcional das fibras. Estudos a cerca do tempo de imobilização sobre os dentes reimplantados e estruturas adjacentes indicam que períodos prolongados são desnecessários, pois não melhoram a cicatrização e podem induzir à reabsorção radicular e à anquilose. A permanência do dispositivo durante duas a três semanas está indicada para injúrias isoladas e durante três a quatro semanas se estiverem associados a fratura óssea ${ }^{10}$.

A terapia antibiótica durante sete a dez dias é justificada pela relação entre o grau de infecção pulpar e reabsorção radicular ${ }^{10}$,

A superfície da raiz deve ser limpa e ficar totalmente sem a presença de fibras periodontais aderentes (e cemento). Outros entram em choque com estas recomendações e insistem na preservação das fibras periodontais e cemento apenas lavando a raiz. Quando a raiz é raspada e feita a remoção das fibras do ligamento periodontal podem ser vistas áreas de reabsorção progressiva da raiz. A indicação ao clínico é de que não raspe a raiz do dente, mas só lave abundantemente e com cuidado, baseada em dados experimentais mesmo que o dente tenha ficado sujo por horas ${ }^{8}$.

Quanto à terapia pulpar a tendência é dar uma chance para que a polpa se mantenha viva, apesar de seu suprimento sangüíneo ter sido removido, ao invés de extirpá-la. Pode-se fazer o teste de vitalidade após 2 a 3 semanas e então executar o tratamento do canal radicular convencional se a polpa estiver necrosada. A polpa raramente é infectada ${ }^{8}$

A manutenção da polpa não é desejada em casos em que o dente tenha forame apical fechado, e a obturação do canal deve ser feita em 2 a 3 semanas após o reimplante. Por outro lado, se o ápice ainda é amplo e o reimplante foi feito em até 2 horas, revascularização pode ser antecipada. 0 adiamento da intervenção endodôntica não é justificado. Entretanto, acompanhamento radiográfico é essencial, visto que a reabsorção radicular inflamatória externa pode ser vista apartir de 3 semanas após o reimplante. $\mathrm{Na}$ maioria dos casos, a 
progressão desse processo é impedida pela remoção imediata da polpa, debridamento do canal e preenchimento temporário com hidróxido de cálcio ${ }^{5}$.

\section{PROGNÓSTICO}

Vários fatores são apontados como determinantes do sucesso, quer influenciando a vitalidade do ligamento periodontal (intervalo de tempo entre avulsão e reimplante, tratamento da superfície radicular e meio de armazenagem), quer interferindo no processo reparador (imobilização e terapia endodôntica) ${ }^{10}$.

Quanto ao prognóstico, Braham, Roberts \& Morris valorizam o esclarecimento aos pais sobre as possíveis seqüelas do reimplante pós avulsão: Anquilose, reabsorção externa e infecção. Embora apresente um prognóstico incerto, o reimplante vem sendo considerado uma medida temporária por muitos, pois a reabsorção radicular surge em 74 a $96 \%$ dos casos como uma complicação ${ }^{10}$.

O prognóstico para dentes reimplantados com respeito à reabsorção por substituição geralmente não pode ser determinado antes do primeiro ano após o trauma, devido à possibilidade de reabsorção por substituição temporária, a menos que o período extra-alveolar seja tão longo que exclua qualquer possibilidade de reparo cicatricial normal do ligamento periodontal ${ }^{1}$.

0 tempo é um fator crítico dentro do quadro prognóstico, pois o sucesso do reimplante é inversamente proporcional ao período extra - oral. Intervalos superiores a duas horas mostram uma porcentagem de reabsorção de $95 \%{ }^{10}$.

Em relação ao período extra-oral, quanto menor, melhor; mas bons resultados podem ser antecipados se o período extra-oral não exceder 30 minutos, e o prognóstico provavelmente não se torna pobre se o dente não foi mantido fora por mais de 90 minutos ${ }^{14}$.

Todos os estudos, em animais e humanos, concordam que o reimplante imediato (com até meia hora após trauma) resulta em percentagem muito alta de restabelecimento dos ligamentos gengivais e periodontais com sucesso ${ }^{8}$. A vitalidade da polpa, especialmente em dentes imaturos com ápice amplamente aberto, também pode ser preservada após reimplante imediato. Depois de 2 a 6 horas, ainda se pode esperar porcentagem alta de restabelecimento com sucesso, mas a preservação da vitalidade pulpar diminui após 2 horas fora da boca. Formação de osteodentina nos canais radiculares é frequientemente vista após 2 a 6 horas fora do alvéolo. Após 6 horas, degeneração pulpar e necrose acontecem mesmo nos dentes imaturos. Entretanto, fibras periodontais e cemento permanecem viáveis (aptos ao restabelecimento e a reagir biologicamente ) para períodos de tempo não muito longos. $\mathrm{O}$ tempo exato pode ser determinado somente em estudos em animais ${ }^{8}$. Em um estudo clínico e radiográfico de 110 dentes reimplantados após perda acidental, foi demonstrado que a reabsorção ocorreu em apenas 10\% dos dentes quando estes foram reimplantados até 30 minutos após o acidente. Se o tempo de reimplante foi de 31 a 90 minutos após o acidente, a reabsorção aconteceu em $57 \%$ dos casos, e se o tempo ultrapassou os 90 minutos, $93 \%$ dos dentes mostraram reabsorção ${ }^{12}$.

Quando a anquilose já está diagnosticada, vários fatores devem ser determinados, isto é, a provável extensão do processo de anquilose e o provável grau de remodelação óssea. Em indivíduos mais velhos com dentes reimplantados e períodos extra-alveolares muito longos, uma maior expectativa de vida do reimplante pode ser antecipada

O elemento reimplantado deve ser gradativamente posto em função, pois o estímulo mastigatório aumenta a incidência do ligamento periodontal normal ${ }^{10}$.

Dentes imaturos com um ápice aberto podem ser retidos, mas, dentes maturos serão logo reabsorvidos, e então, seu reimplante será inútil ${ }^{8}$.

Quase todos os estudos concordam que dentes imaturos respondem melhor que dentes maduros. Entretanto, a diferença não é tão grande para que o dente maduro seja condenado antes que se tente o tratamento conservador. Dentes adultos reagem mais vagarosamente quando comparados com dentes imaturos depois do reimplante imediato, mas a diferença entre eles é pequena se o reimplante se dá com mais de 24 horas de permanência do dente fora da boca ${ }^{8}$.

É comum que um dente reimplantado sobreviva por 1 a 5 anos, acabando por ser exfoliado devido à reabsorção. Numa amostra total de 110 dentes observados por Andreasen e Hjorting-Hansen, sem considerar tempo extra-oral, condições do ligamento periodontal ou se o tratamento endodôntico foi feito; 84 (76\%) sobreviveram por um ano, 59 (54\%) duraram dois anos, 39 (35\%); três anos, 36 (33\%); quatro anos e $26(24 \%)$ ainda eram funcionais após cinco anos ${ }^{14}$.

Em alguns casos o reimplante é con- tra-indicado. Isso geralmente é verdadeiro quando o dente foi fraturado por cáries ou quando o ligamento periodontal foi gravemente reduzido devido a periodontite marginal. Grave apinhamento da área é sinal de mau prognóstico, poderia levar à decisão de não reimplantar o dente avulsionado ${ }^{1}$.

\section{CONDUTAS ORTODÔNTICAS EM DENTES TRAUMATIZADOS}

A orientação dada em injúrias moderadas ou severas (extrusão, intrusão, luxação lateral e avulsão) é que o período de observação seja no mínimo de um ano, pois, as sequielas dos traumatismos aparecem, geralmente durante este período de tempo ${ }^{18}(\mathrm{Fi}-$ guras 5 e 6).

Se está indicado um tratamento endodôntico, a movimentação ortodôntica do dente deve ser adiada, até que sejam aparentes, radiograficamente, os sinais de reparação da raiz ${ }^{18}$.

Os dentes que foram lesados por traumatismos são provavelmente, mas não necessariamente, mais passíveis de reabsorção da raiz que os dentes que não sofreram injúria. $\mathrm{O}$ tipo e a severidade da injúria devem ser considerados ${ }^{18}$. Em estudo realizado por Linge e Linge ${ }^{6}$, a reabsorção apical tem sido relatada frequentemente como resultado de trauma incisal (Andreasen, 1981), e pode ocorrer com o passar de alguns meses. Nenhuma distinção é feita entre trauma de um só dente e trauma dos incisivos superiores. Como um grupo, os pacientes traumatizados mostraram significativamente mais reabsorção radicular.

Gordon ${ }^{4}$, estudando reimplantes realizados em macacos sendo submetidos à tração ortodôntica, observou a presença de extrema reabsorção de cemento e severa reabsorção irregular de dentina, e freqüentemente, destruição quase total do ligamento periodontal. Estes dentes mostraram mais anquilose que os outros dentes anteriores. Entretanto, na extremidade dos dentes que não foram reimplantados, mas foram tracionados, o cemento também foi reabsorvido.

A tração ortodôntica não tem capacidade de reposicionar um dente anquilosado, mas pode causar uma movimentação indesejável dos dentes de ancoragem ${ }^{18}$.

Outra alternativa seria uma luxação intencional para quebrar a ponte óssea entre cemento e o osso mas, geralmente, resulta numa reanquilose. Provavelmente, é mais efetiva quando combinada com a extrusão ortodôntica (obteve-se sucesso no tratamento de alguns pré-molares autotransplantados anquilosados com esse tipo de procedimento) ${ }^{18}$. 

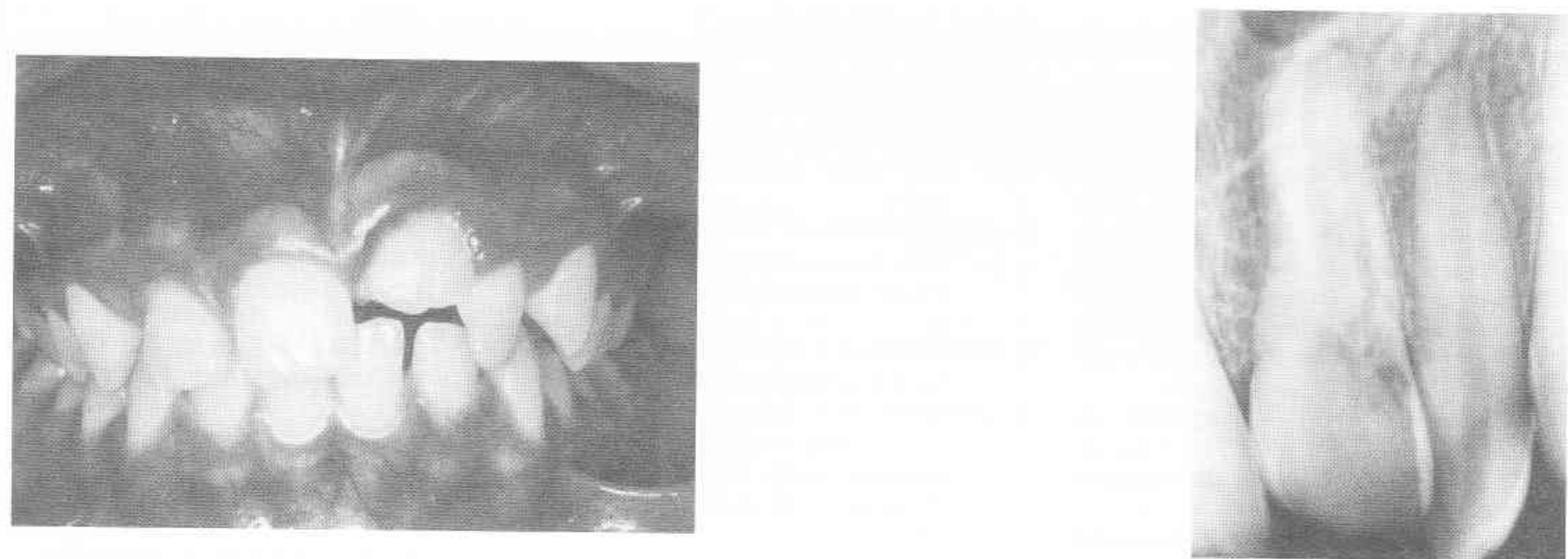

Fig. 1 e 2: Vista intra-oral de frente e aspecto radiográfico de um caso de avulsão, reimplante e posterior anquilose do incisivo central superior esquerdo.
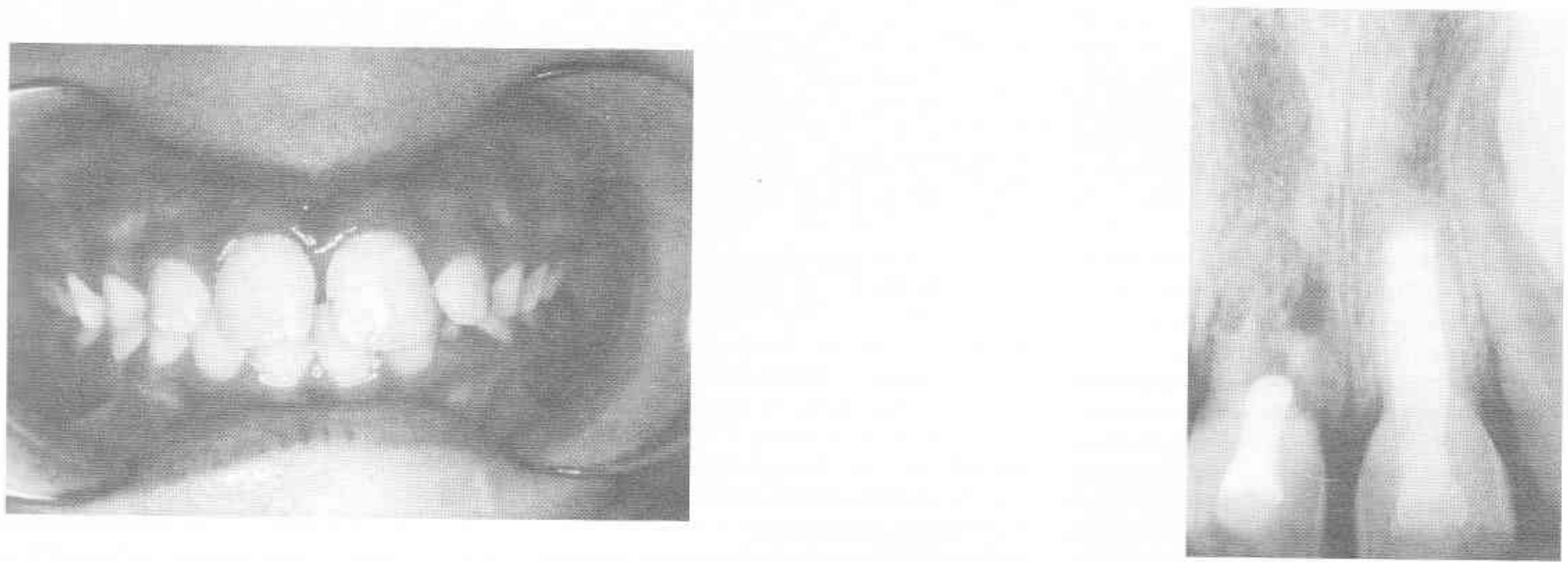

Fig. 3 e 4: Vista intra-oral de frente e aspecto radiográfico de um caso de avulsão e reimplante com posterior reabsorção das raízes dos incisivos centrais superiores.
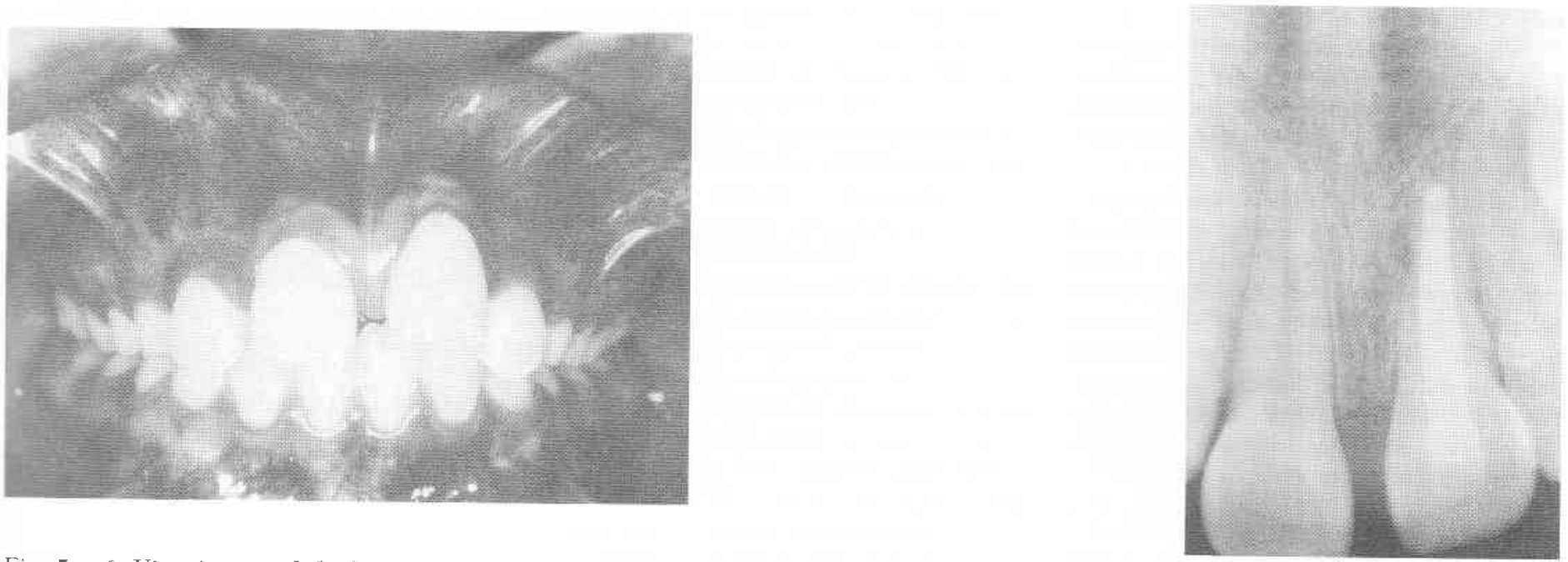

Fig. 5 e 6: Vista intra-oral de frente e aspecto radiográfico de um caso de avulsão, reimplante e tratamento endodôntico convencional do incisivo central superior esquerdo (controle de um ano após o traumatismo). 


\section{Conclusão}

De um modo geral, quanto maior for o trauma, maior será a chance de reabsorção radicular durante a movimentação ortodôntica. Em particular, as luxações graves e as avulsões seguidas de reimplante, são de alto risco.

Sempre que um incisivo central superior sofrer um golpe, os dentes vizinhos também podem ser afetados e mostrar reações mais tarde, durante o período de tratamento ortodôntico. Esse fato deve ser levado em consideração.

$A$ anquilose, seqüela freqüente em dentes reimplantados, é um problema clínico que inviabiliza o movimento dentário ortodôntico.

Observações clínicas mostram que dentes tratados endodonticamente podem ser movimentados por forças ortodônticas sem respostas adversas excessivas. Quanto mais severo é o traumatismo, pior será o prognóstico destes dentes tratados endodonticamente durante a terapia ortodôntica. A análise radiográfica mostra uma maior incidência de reabsorção radicular em dentes tratados endodonticamente quando comparados a um dente adjacente com vitalidade. 0 movimento ortodôntico é seguro, exceto em casos de reimplante ou traumatismo severos, o ortodontista deve estar apto a incluir esses dentes com tratamento endodôntico no plano de tratamento.

Dentes que desenvolveram anquilose durante o período de observação pós traumática (antes do tratamento ortodôntico) devem receber tratamento endodôntico imediato e serem acompanhados até a reabsorção ser controlada. A reabsorção por substituição em dentes traumatizados é progressiva e o dente não responde ao movimento ortodôntico.

\section{SUMMARY}

Based on a literature review, the objective of this study is to establish the degree of dental ankylosis or root resorption that allows replanted teeth to be moved using orthodontic appliance.

Some aspects of avulsion and replanted teeth such as etiology, clinical aproach and prognosis are considered. It is also presented a literature review of orthodontic tooth movement. According to most authors, the replant is frequently followed by ankylosis that doesn't allow orthodontic movement. Nevertheless, the lack of resorption signs during a minimum period of one year allows orthodontic treatment when necessary.

\section{KEYWORDS}

Ankylosis, tooth moviment, tooth replantation.

\section{REFERÊNCIAS BIBLIOGRÁFICAS:}

1. ANDREASEN, J.O. Atlas de reimplante e transplante dental. São Paulo: Panamericana, 1993. $303 \mathrm{p}$.

2. ANDREASEN, J.O. ; ANDREASEN, F.M. Traumatismo dentário. São Paulo: Panamericana, 1991. 168 p.

3. FERREIRA, F.V. Ortodontia. São Paulo: Artes Médicas, 1996. 495p.

4. GORDON, N. S. Effect of orthodontic force upon replanted teeth: a histologic study. Am. J. Orthod., St. Louis, v. 62 , n. 5 , p. 544, Nov. 1972.

5. JACOBSEN, I. Clinical problems in the mixed dentition: traumatized teeth - evaluation, treatment and prognosis. Int. Dent. J., Guildford, v. 31, n. 2, p. 99-104, June 1981.

6. LINGE, B.O.; LINGE, L. Apical root resorption in upper anterior teeth. Europ. J. Orthod., London, v. 5, n. 3, p. 173-183, Aug. 1983.

7. MALMGREN, O.; GOLDSON, L.; HILL, C et al. Root resorption after orthodontic treatment of traumatized teeth. Am. J. Orthod., St. Louis, v. 82, n. 6, p. 487-491, Dec. 1982.

8. MASSLER, M. Tooth reimplantation. Dent. Clin. North Am., Philadelphia, v. 18, n. 2, p. 445452, Apr. 1974.

9. MELO, L.L. Traumatismo alvéolodentário. São Paulo: Artes Médicas, $1998.287 \mathrm{p}$.

10. MOREIRA, T.C. Condutas clínicas para o reimplante de dentes permanentes avulsionados. Ortodontia Gaúcha, Porto Alegre, v. 2, n. 1, p. 50-57, jan./jun. 1998.

11. MOYERS, R.E. Ortodontia. 4. ed. Rio de Janeiro: Guanabara Koogan, 1991. 483 p.

12. PINDBORG, J.J. Pathology of the dental hard tissues. Copenhagen: Munksgaard, 1970. $443 \mathrm{p}$.

13. POPP, T.W.; ARTUN, J.; LINGE, L. Pulpal response to orthodontic tooth movement in adolescents: $A$ radiographic study. $\boldsymbol{A m}$. $\boldsymbol{J}$. Orthod. Dentofac. Orthop., St Louis, v. 101, n. 3, p. 228-233, Mar. 1992.

14. SCOTT, J.N.; ZELIKOW, R. Replantation - a clinical philosophy. J. Am. Dent. Assoc., Chicago, v. 101, n. 1, p. 17-19, July/Dec.
1980.

15. TURLEY, P.K.; CRAWFORD, L.B.; CARRINGTON, K.W. Traumatically intruded teeth. Angle Orthod.,Appleton, v.57, n. 3, p. 234-244, July 1987.

16. TURPIN, D.L. The orthodontist's role in managing traumatic dental injuries. Angle Orthod., Appleton, v. 62, n. 2, p. 83-84, Summer 1992.

17. WICKWIRE, N.A.; McNEIL, M.H.; NORTON, L.A et. al. The effects of tooth movement upon endodontically treated teeth. Angle Orthod., Appleton, v. 44, n. 3, p. 235-242, July 1974.

18. ZACHRISSON, B. U. Em busca da excelência na ortodontia. Bragança Paulista: Editora da Universidade São Francisco, 1989. 155p.

\section{AGRADECIMENTOS}

A Antônio Furlan dos Santos pela orientação na revisão dos textos de Endodontia.

A Viviane Zys, Fábio Fuhr e Daniela Fortes pelos casos clínicos cedidos para ilustração do trabalho.

Endereço para correspondência:

Daniela Soeiro de Souza Rezende Av. Goethe, no 5 sala 403

90430-100 - Porto Alegre - RS

Fone: (51) 3463251

e-mail: danirezende@hotmail.com 